American Journal of Pharmaceutical Education 2019; 83 (10) Article 7011.

\title{
RESEARCH
}

\section{Virtual Pharmacy Programs to Prepare Pharmacy Students for Community and Hospital Placements}

\author{
Cherie Lucas, PhD, Kylie Williams, $\mathrm{PhD}$, Beata Bajorek, $\mathrm{PhD}$ \\ University of Technology Sydney, Graduate School of Health, Sydney, Australia \\ Submitted February 2018; accepted May 2019; published December 2019.
}

Objective. To explore and evaluate pharmacy students' perceptions of the value and relevance of virtual community and virtual hospital on-campus placement programs.

Methods. Students enrolled in a Master of Pharmacy program completed the required Virtual Community Placement (VCP) program and/or the Virtual Hospital Placement (VHP) program. A six-item questionnaire was administered to students after completion of each of the virtual programs to elicit students' perceptions of the value and relevance of the virtual programs. Additional data related to the relevance of specific workshops were collected, including students' self-reported confidence levels to undertake placement in a real-world setting following completion of the virtual programs.

Results. Surveys were completed by 61 students in the VCP program and 50 students in the VHP program. Students perceived the virtual programs to be beneficial, with the majority ( $84 \%$ of the VCP students and $98 \%$ of the VHP students) reporting that the programs should be an essential component of any pharmacy degree. The majority of students (72\%) self-reported an increase in their confidence levels in undertaking a real-world experiential placement after they completed their virtual hospital placement.

Conclusion. Completing virtual placement programs prior to pharmacy students beginning their first "real world" pharmacy placements had a positive effect on student learning and confidence levels. Pharmacy students' feedback from this study regarding the relevance of specific learning modules and laboratory sessions will inform future curriculum development of the virtual placement programs.

Keywords: experiential placements, pharmacy education, simulation, pharmacy program

\section{INTRODUCTION}

Simulation and virtual activities play a pivotal role in educating health care professionals and are a useful forum in which students can practice the application of knowledge and skills without causing any risk or harm to a patient. ${ }^{1-4}$ Although simulation activities cannot replicate authenticity, ${ }^{1}$ they do provide a means of familiarizing students with a new environment. Programs that incorporate simulation in health care and pharmacy education may use several different strategies depending on the level of technology available and the skillset to be developed. ${ }^{5}$ These strategies can range from the use of online tools such as YouTube educational resources, video game-like dispensing simulators that use virtual patients, ${ }^{6-9}$ hands-on laboratories to practice techniques and/or use specific equipment such as point-of-care testing devices, role plays using standardized patients, ${ }^{1-5}$

Corresponding Author: Cherie Lucas, Graduate School of Health, University of Technology Sydney, 100 Broadway, Ultimo, 2008, Sydney, NSW, Australia. Tel: +61 29514 4275. Email: cherie.lucas@uts.edu.au. lived-experience patients, and/or virtual patients in standardized clinical cases, ${ }^{9,10}$ filming techniques to enhance counselling skills ${ }^{11}$ and self-reflection, ${ }^{5}$ and simulated community and hospital environments. Some of these environments simulate "authentic" pharmacy settings and come fully equipped with wound care products, medications, and dispensing software systems. ${ }^{1}$ Likewise, some virtual hospital environments may use highfidelity human simulators (mannequins) that simulate physiological responses that can be assessed using human monitoring devices, eg, a syphgmometer.,

Virtual placement program is the umbrella term used at the University of Technology Sydney (UTS) for programs that incorporate simulation activities tailored to emulate either the community pharmacy or hospital pharmacy setting. Virtual placement programs place students into an environment in which they can engage in a range of simulated activities. Furthermore, as part of the virtual placement programs, students are involved in other authentic practice-based activities such as point of care testing, handling of non-prescription products, 


\section{American Journal of Pharmaceutical Education 2019; 83 (10) Article 7011.}

vaccination training, and completing interactive online learning modules (professional development activities). Virtual placement programs are intensive one- to twoweek programs that use resources available at our institution (eg, simulation hospital wards, programmable mannequins, real blood pressure devices) and are conducted prior to students beginning their experiential placements. Related terminology has been described in the literature for other pharmacy schools, however, there is inconsistency as to what is included in a virtual pharmacy practice program. For example, an article from another Australian university describes a specialized teaching space allocated to the enhancement of students' communication and interpersonal skills through a virtual practice environment (VPE). ${ }^{11}$ The VPE uses advanced technology and software to display "life-size" photographic and video imagery that uses $33 \%$ of a wall space, providing a "realistic view" of a sample environment, for example, images of a community pharmacy environment. ${ }^{11}$ There are many advantages to this virtual learning space which includes easy adaptation of the environment by changing the "backdrop" to keep up with changes in the real world. Another advantage to this type of technology is the limited physical space it requires. However, it is not a platform for students to obtain "hands-on" experience, such as the handling or preparation of medication. ${ }^{11}$ In related research conducted at the University of Wisconsin (UW), another type of virtual program using an online learning platform was developed to instruct pharmacy students and practitioners to provide appropriate medication therapy management (MTM) via the use of virtual patients. ${ }^{12}$ Similarly, a virtual patient pilot program has been developed to assist pharmacy students with disease state management (DSM). That program involves students having 24-hour use of a web site which they access using a unique code and then interact with their virtual patients from a "virtual waiting room." ${ }^{\text {None }}$ of these virtual programs are organized as a course, but rather as a program conducted over the course of a semester. For example, the VPE program is delivered in the form of four 3-hour sessions consisting of tutorials, and laboratory sessions held over a 10 -week period. ${ }^{11}$ In contrast, the virtual patient software program is delivered over the course of a seven-week seminar block. ${ }^{9}$ As these examples illustrate, there is wide variation in the strategies and delivery of simulation programs used in health care professional education. Similarly, there is no "one model fits all" approach to simulations as part of the virtual placement program for pharmacy education. Neither is there any related research into the effect on students' confidence levels and perceived learning of an intensive program delivered prior to students attending their first experiential placements. Hence, student perceptions of such programs, their value and perceived impact on students' confidence levels, must be assessed to inform future curriculum development of virtual placements. Furthermore, with increased student cohort sizes and increased demand to secure experiential placements, virtual simulation programs may also be used in the absence of a sufficient number of placement sites.

Virtual placements are delivered on campus at different stages of the Master of Pharmacy degree at UTS, Australia. The Virtual Community Placement (VCP) program and the Virtual Hospital Placement (VHP) program both use simulation environments, standardized patients (trained individuals depicting patients' medical conditions, with signs and symptoms tailored to each case) ${ }^{9}$ and online tools to prepare students for the "real world" context of the simulations.

Clinical Practice 1 is a compulsory six-credit unit of study (UoS) delivered to first-year Master of Pharmacy (MPharm) students during the first semester (14 weeks) of the degree program. As students are expected to begin their first experiential placement in a community pharmacy setting in week 2, the VCP is an intensive five-day program completed during week 1 to prepare them. During the program, students acquire some basic community pharmacy knowledge, hands-on skills using standardized patients, and an understanding of the processes they will encounter in community pharmacy settings.

Clinical Practice 3 is a compulsory six-credit unit delivered midway through the MPharm degree program. This unit of study focuses on students developing clinical and analytical skills that are pertinent to the hospital setting, thereby preparing them for their first experiential placements in hospitals. The VHP involves a two-week intensive educational program that includes activities such as simulation with standardized patients, online learning and assessment tasks, and hands-on activities such as point-of-care testing, blood pressure monitoring, etc. All face-to-face activities are conducted on campus.

The aims of this study were to explore pharmacy students' perceptions (value and relevance) of the current VCP and VHP on-campus placement programs and their perceived impact of the program(s) on their confidence levels to undertake a real-world placement following completion of the virtual placements.

\section{METHODS}

Before commencing this study, approval was obtained from the Human Research Ethics Committee of the University of Technology Sydney. All students enrolled in the MPharm degree program were required to participate in the virtual placement programs. However, 


\section{American Journal of Pharmaceutical Education 2019; 83 (10) Article 7011.}

participation in the evaluation of the educational programs as part of this study was voluntary. All students who were enrolled in Clinical Practice 1 and Clinical Practice 3 in 2017 were invited at the beginning of each unit to participate. A participant information statement indicating that nonparticipation in the study would not affect their grades was provided to all students prior to the study. Students were not offered any incentive to participate.

Both virtual placement programs (VCP and VHP) were evaluated by students after they had participated in each respective program. Both evaluations involved an anonymous six-item student survey with items rated on a six-point Likert-type scale. Responses on the Likert-type scale ranged from strongly disagree $=1$ to strongly agree $=6$. A six-point Likert-type scale was chosen so that students could not select a neutral response to any question. The survey also included questions on specific laboratories to obtain students' perceptions of their relevance. Finally, the survey asked students to rate their confidence level in undertaking a community and/or hospital experiential placement prior to and after completing the virtual on-campus placement program.

The descriptive statistics gathered included the number and percentages of students in agreement with statements related to the perceived value and relevance of the virtual placement program(s). Data were analyzed using SPSS, version 20 (IBM, Armonk, NY). ${ }^{13}$ Two researchers reviewed the data. Integrity of the data were maintained with the data analyzed, and raw data and data entry were independently checked for discrepancies by another research assistant, who also ran the statistical procedures again. Students' reported self-confidence levels were assigned a score by the lead researcher. This score was based on students' self-reported level of confidence after they completed the virtual program(s). For example, if students indicated that they were not confident in their ability to undertake an experiential placement, a score of 1 was given $(1=$ not confident, $2=$ confident and $3=$ very confident). The Wilcoxon singed ranked test was employed to identify students' self-reported confidence levels and changes after they had completed the virtual placement program(s). Significance level was set at $p<.05$.

\section{RESULTS}

From a cohort of 65 students enrolled in the virtual community placement program (VCP), 61 students completed the evaluation (response rate $94 \%$; female $=$ $36)$. An overwhelming majority of students (98\%) agreed (comprising strongly agreed [SA], agreed [A] and/or mildly agreed [MA] with question 1, "The VCP assisted me with the processes that are involved in a Community Pharmacy setting." Most students (80\%) disagreed (ie, mildly disagreed, disagreed and/or strongly disagreed) with question 2, "The VCP was a waste of time," indicating that they valued the time spent participating in the VCP program. The vast majority of students $(97 \%)$ agreed (SA, A, and MA) with question 3, "The VCP enabled me to become more familiar with the expectations required of me as a student for placement." Most students (89\%) agreed (SA, A, and MA) with question 4, "The VCP helped me understand how I can utilize my time better on placement." The majority of students (84\%) agreed (SA, A, and MA) with question 5, "The VCP made me feel more comfortable about starting a new placement." The majority of students (84\%) agreed (SA, A, and MA combined) with question 6, "The VCP should be an essential component of any pharmacy degree." Table 1 shows pharmacy students' perceptions of the VCP.

In addition to the laboratory training module on the scheduling of medications, other laboratories and sessions in the VCP that students found highly relevant included the pharmacy tour, where students were shown various areas of the pharmacy and the products that are kept in those areas; Q\&A session with preceptor pharmacists, in which students were able to ask questions of current preceptors regarding their expectations about placement and gain a better understanding of a day in the life of a community pharmacist; "Useful Pharmacy Resources," a laboratory session that assisted students with identifying the appropriate resources for information on different medications (including prescription, nonprescription, and herbal); the blood pressure monitoring laboratory, where students obtained hands-on experience by measuring each other's blood pressure; strategies to utilize to being productive in the pharmacy, where students workshopped various scenarios to gain a better understanding of how to be more productive in a busy or quiet pharmacy; a dispensing laboratory, which provided students with their first exposure to the procedure and hands-on practice; "Reflection on Practice Laboratory," where students were exposed to the foundation of how to critique their practice using a unique online reflective writing tool. ${ }^{14}$ Table 2 shows pharmacy students' perceptions of the relevance of specific laboratory sessions conducted during the VCP. In terms of self-reported confidence levels, the Wilcoxon signed rank test indicated that the post-test scores for the virtual community placement were significantly higher than the pretest scores $(\mathrm{z}=-4.6$, $p<.05$ ), with $36 \%$ of students indicating an increase in their confidence level after completing the virtual community placement. 


\section{American Journal of Pharmaceutical Education 2019; 83 (10) Article 7011.}

Table 1. Student Perceptions of the Virtual Community Placement (VCP)

Instructions: Circle the appropriate number that indicates to what extent to which you agree with the following statements regarding the Virtual Community Placement (VCP)

Assisted me with the processes that are involved in a Community Pharmacy Setting

Was a waste of time

Enabled me to become more familiar with the expectations required of me as a student for Community Pharmacy placement

Helped me understand how I can utilize my time better on placement

Made me feel more comfortable about starting a new placement

Should be an essential component of any pharmacy degree

$1=$ strongly disagree, $2=$ disagree, $3=$ mildly disagree, $4=$ mildly agree, $5=$ agree, $6=$ strongly agree

Data from Q2 (was a waste of time) was flipped during analysis to represent the positive orientation of this negative question

From a cohort of 56 students enrolled in the virtual hospital placement (VHP) program, 50 students completed the evaluation (response rate $89 \%$; male $=16$, female $=34)$. All students $(100 \%)$ agreed (strongly agreed, agreed, and/or mildly agreed) with question 1 , "The VHP assisted me with the processes that are involved in a Hospital Pharmacy setting." The majority of students (88\%) disagreed with question 2, "The VHP was a waste of time. The entire cohort $(100 \%)$ of students agreed (SA, A, and MA) with Question 3, "The VHP enabled me to become more familiar with the expectations required of me as a student for placement." The majority of students (96\%) agreed with Question 4, "The VHP helped me understand how I can utilize my time better on placement." The majority of students (98\%) agreed (SA, A, and MA) with Question 5, "The VHP made me feel more comfortable about starting a new placement." The vast majority of students (98\%) agreed with Question 6 "The VHP should be an essential component of any pharmacy degree." Pharmacy students' perceptions of the VHP are presented in Table 3. Students perceived the following laboratory sessions in the VHP as most relevant: orientation to the hospital environment; interprofessional simulation laboratory sessions; vaccination training; adrenaline auto-injector training; pointof-care testing; and laboratories related to medication chart review; and citation and medication reconciliation (including charting abbreviations). Table 4 displays perceptions of the relevance of specific laboratory sessions conducted as part of the VHP. In terms of students' self-reported confidence levels, the Wilcoxon signed rank test indicated that posttest scores were significantly higher than pretest scores $(Z=-5.5$, $p<.05$ with the majority of students $(36 / 50,72 \%)$ reporting an increase in their confidence level after completing the virtual hospital placement, including three students who indicated that they had started with no confidence and progressed to being very confident (self-reported a confidence level 3) after completing the placement.

Table 2. Student Perceptions of the Relevance of VCP Laboratories $(\mathrm{N}=61)$

\begin{tabular}{|c|c|c|c|}
\hline Curricular Content & Very Relevant, \% & Somewhat Relevant, \% & Not Relevant, \% \\
\hline Pharmacy Tour & 52 & 43 & 5 \\
\hline BP monitoring & 51 & 41 & 8 \\
\hline Q\&A session with preceptors & 56 & 41 & 3 \\
\hline Useful Pharmacy Resources & 67 & 30 & 3 \\
\hline Being Productive in Pharmacy & 41 & 57 & 2 \\
\hline $\begin{array}{l}\text { Student Experiences (Rural Community } \\
\text { Pharmacy) }\end{array}$ & 43 & 43 & 14 \\
\hline $\begin{array}{l}\text { Student Experience (Non-Rural Community } \\
\text { Pharmacy) }\end{array}$ & $41^{\mathrm{a}}$ & $39^{\mathrm{a}}$ & $13^{\mathrm{a}}$ \\
\hline Scheduling of Drugs Training Session (S2 and S3) & 92 & 7 & 1 \\
\hline $\begin{array}{l}\text { Introduction to Dispensing and dispensing } \\
\text { software }\end{array}$ & 61 & 36 & 3 \\
\hline $\begin{array}{l}\text { Demonstration and Laboratory (ROWA: Robotic } \\
\text { Dispensing) }\end{array}$ & 25 & 48 & 27 \\
\hline Reflection on Practice & $43^{\mathrm{b}}$ & $52^{\mathrm{b}}$ & $3^{\mathrm{b}}$ \\
\hline
\end{tabular}

${ }^{a} 8$ students did not provide an answer to this question

b 1 student did not provide an answer to this question 


\section{American Journal of Pharmaceutical Education 2019; 83 (10) Article 7011.}

Table 3 Student Perceptions of the Virtual Hospital Placement (VHP)

Instructions: Circle the appropriate number that indicates to what extent to which you agree with the following statements regarding the Virtual Hospital Placement (VHP)

Assisted me with the processes that are involved in a Hospital Pharmacy Setting

Was a waste of time

Enabled me to become more familiar with the expectations required of me as a student for Hospital Pharmacy placement

Helped me understand how I can utilize my time better on placement

Made me feel more comfortable about starting a new placement

Should be an essential component of any pharmacy degree

$1=$ strongly disagree, $2=$ disagree, $3=$ mildly disagree, $4=$ mildly agree, $5=$ agree, $6=$ strongly agree

Data from Q2 (was a waste of time) was flipped during analysis to represent the positive orientation of this negative question

\section{DISCUSSION}

While simulation has been incorporated into the curriculum at many pharmacy schools, ${ }^{2-9,11}$ the idea of intensive virtual placement programs prior to students beginning their experiential placements is still a relatively new concept for some Australian pharmacy schools. Furthermore, the terminology, content, and delivery of these types of programs differ across pharmacy schools nationally and internationally, with some tailored to the context and/or competency standards where the program is located. ${ }^{9,11,12}$ For example, students undertaking a virtual placement program at an Australia university may also be involved in completing a training laboratory, learning proper handling of products, and attending didactic lectures related to the scheduling of medications, some of which may only be applicable to Australian pharmacy programs.

This study aimed to explore pharmacy students' perceptions of the value and relevance of the virtual placement programs targeting community and hospital

Table 4. Bachelor of Pharmacy Students' Perceptions of the Relevance of VHP Workshops and Laboratory Sessions $(\mathrm{N}=50)$

\begin{tabular}{|c|c|c|c|}
\hline Curricular Content & Very Relevant, \% & Somewhat Relevant, \% & Not Relevant, \% \\
\hline Orientation to the Hospital Environment & $88^{\mathrm{a}}$ & $10^{\mathrm{a}}$ & 0 \\
\hline Practice Case Reviews & 56 & 42 & 2 \\
\hline Interprofessional (IPE) Simulation Labs & 96 & 4 & 0 \\
\hline Online Pharmacy Modules (NPS/PSA/SHPA) & 54 & 40 & 6 \\
\hline $\begin{array}{l}\text { Anaphylaxis Training for Health Professionals- } \\
\text { Online modules }\end{array}$ & 68 & 28 & 4 \\
\hline Workshop on needles and syringes & 70 & 30 & 0 \\
\hline $\begin{array}{l}\text { Current Practising Pharmacists presenting } \\
\text { current cases }\end{array}$ & 66 & 32 & 2 \\
\hline Day in the Life of a Hospital Pharmacist & 70 & 30 & 0 \\
\hline Research in Hospital settings & 44 & 48 & 8 \\
\hline Medication Reconciliation Workshop & 72 & 26 & 2 \\
\hline Medical Abbreviations Workshop & 72 & 28 & 0 \\
\hline Pathology & 70 & 30 & 0 \\
\hline Medication Chart Considerations & 82 & 18 & 0 \\
\hline Hospital Dispensing & 72 & 26 & 2 \\
\hline $\begin{array}{l}\text { Crucial Conversations- How to deal with } \\
\text { discrepancies }\end{array}$ & 70 & 30 & 0 \\
\hline HIV/AIDS case & 40 & 54 & 6 \\
\hline IPE online YouTube Cases & 54 & 40 & 6 \\
\hline Medication Safety Workshop and Lecture & 70 & 28 & 2 \\
\hline Vaccination training and Epipen training & 92 & 8 & 0 \\
\hline $\begin{array}{l}\text { Q and A session with current hospital preceptors } \\
\text { and pharmacists }\end{array}$ & 70 & 26 & 4 \\
\hline $\begin{array}{l}\text { Point of Care Testing (INR, Cholesterol, Blood } \\
\text { Glucose) }\end{array}$ & 78 & 22 & 0 \\
\hline
\end{tabular}

Abbreviations: IPE $=$ interprofessional education;

${ }^{a}$ One student did not provide an answer to this question 


\section{American Journal of Pharmaceutical Education 2019; 83 (10) Article 7011.}

settings and their associated laboratory sessions, and learning modules. Additionally, the study reported on the changes in student self-reported confidence level to undertake a "real-world" experiential placement following their participation in these programs. The findings of this study show that the current laboratory sessions in both programs (VCP and VHP) were well received by the students, given that the majority of students indicated that these programs helped them become more familiar with the processes, expectations, and possible future activities for each of the different working environments (community pharmacy and hospital pharmacy). This is consistent with previous research on virtual programs and the use of virtual environments, which have had positive impacts on student learning. ${ }^{9,11}$ Furthermore, the majority of students rated all laboratory sessions as very relevant or somewhat relevant, with a minority addressing two particular laboratory sessions in the VCP as not relevant. One of the two laboratory sessions related to the Rural Community Pharmacy Student Experience where the previous cohort of students presented their experience and work in that particular area. The students who indicated this laboratory session as not relevant may have not been interested in attending a rural/remote placement. Conversely, students who were more interested in attending a rural placement may have given the session a higher score for relevance. The laboratory that some students thought was not as relevant was a demonstration on robotic dispensing equipment. Those students may have perceived the information as something they may not be required to use in practice as pharmacies with a robotic dispensing machine are not as prominent as those without.

In the VCP, the majority of students rated positively all laboratory sessions that were hands on and/or immediately relevant to their upcoming placements. For example, an overwhelming majority of students perceived the laboratory on scheduling of medications as very relevant. Similarly, in the VHP, the majority of students perceived interactive and hands-on learning modules such as the interprofessional simulation laboratory as a positive learning experience and relevant to future practice. The highest ratings for relevance were attained for the interprofessional simulation laboratory. This result indicated that the students valued their experience of being in a hospital-like environment that mimicked the "real-world" context and valued interactions with other health professions students. This is in line with previous studies in interprofessional education (IPE) and interprofessional learning (IPL). ${ }^{15-18}$ Many of the virtual programs discussed in the literature relate to virtual learning rather than hands-on active learning within a virtual space. Perhaps more programs embedding handson experiences within the virtual learning spaces would be beneficial.

The majority of students reported increased confidence levels to undertake a future experiential hospital placement. The vast majority of students perceived that these programs should be an essential part of the pharmacy curriculum that is completed prior to students entering "real-world" pharmacy practice environments. Future research investigating how virtual placement programs impact student progression through the degree, how these students perceive virtual placement programs after completing "real-world" placements, and how oncampus placements assist with pharmacy student learning and development would be advantageous.

One limitation of this study was that it involved only one cohort of pharmacy students from one institution who participated in a program unique to that institution. Perceptions of students from other universities and colleges may differ, therefore these results cannot be generalized. Another limitation was that no comparisons were investigated post rotation(s) from either students and/or preceptors. Future plans to extend the current program include creating an extended virtual program to embed professionals from a variety of different disciplines so that students can be exposed to different perspectives and professional opinions from a diverse group of health professionals; and comparing students' perceptions with the value and relevance of such programs with a pre-test (prior to rotation) post-test design (after completing a rotation).

\section{CONCLUSION}

Master of Pharmacy students at an Australian university perceived virtual on-campus placement programs as valuable and relevant to their future experiential placement. Students' self-reported confidence levels to undertake a real-world experiential placement increased after they participated in the intensive virtual community and virtual hospital programs. These types of on-campus placements offer an opportunity for students to become more familiar with the proposed environments and the types of health professionals they may interact with in their real-world placements. The findings from this study will inform future development and enhancement of future virtual placement programs.

\section{ACKNOWLEDGMENTS}

The authors would like to acknowledge the pharmacy students from the Master of Pharmacy, Graduate School of Health. The authors would like to extend their gratitude to $\mathrm{PhD}$ student and research assistant, Paul Lee, who independently checked for discrepancies in the data. 


\section{American Journal of Pharmaceutical Education 2019; 83 (10) Article 7011.}

\section{REFERENCES}

1. Wilbur K, Wilby KJ, Pawluk S. Pharmacy preceptor judgments of student performance and behavior during experiential training. Am J Pharm Educ. 2018;82(10):Article 6451.

2. Tofil NM, Benner KW, Worthington MA, Zinkan L, White ML. Use of simulation to enhance learning in a pediatric elective. Am J Pharm Educ. 2010;74(2):Article 21.

3. Seybert AL, Barton CM. Simulation-based learning to teach blood pressure assessment to doctor of pharmacy students. Am J Pharm Educ. 2007;71(3):Article 48.

4. Seybert AL, Laughlin KK, Benedict NJ, Barton CM, Rea RS. Pharmacy student response to patient-simulation mannequins to teach performance-based pharmacotherapeutics. Am J Pharm Educ.

2006;70(3): Article 48.

5. Lin K, Travlos DV, Wadelin JW, Vlasses PH. Simulation and introductory pharmacy practice experiences. Am J Pharm Educ. 2011;75(10): Article 209.

6. Ferrone M, Kebodeaux C, Fitzgerald J, Holle L. Implementation of a virtual dispensing simulator to support US pharmacy education. Curr Pharm Teach Learn. 2017;9:511-520.

7. Jabbur-Lopes MO, Mesquita AR, Silva LMA, De Almeida Neto

A, Lyra Jr DP. Virtual patients in pharmacy education. Am J Pharm Educ. 2012;76:1-8.

8. Smith MA, Waite LH. Utilization of a virtual patient for advanced assessment of student performance in pain management. Curr Pharm Teach Learn. 2017;9(5):893-897.

9. Douglass MA, Casale JP, Skirvin JA, DiVall MV. A virtual patient software program to improve pharmacy student learning in a comprehensive disease management course. Am J Pharm Educ.

2013;77(8):Article 172
10. Marriott J. Use and evaluation of virtual patients for assessment of clinical pharmacy undergraduates. Pharm Educ.

2007;7(4):341-349.

11. Hussainy SY, Styles K, Duncan G. A virtual practice environment to develop communication skills in pharmacy students. Am J Pharm Educ. 2012;76(10):Article 202.

12. Battaglia JN, Kieser MA, Bruskiewitz RH, Pitterle ME, Thorpe JM. An online virtual-patient program to teach pharmacists and pharmacy students how to provide diabetes-specific medication therapy management. Am J Pharm Educ. 2012;76(7):Article 131. 13. IBMCorp. IBM SPSS Statistics for Windows. Version 20.0. Armonk, NY: IBM Corp; Released 2011.

14. Gibson A, Aitken A, Sandor A, Buckingham Shum S, TsingosLucas C, Knight S. Reflective writing analytics for actionable feedback. Proceedings of LAK17: 7th International Conference on Learning Analytics and Knowledge, March 13-17, 2017, Vancover, Canada. 15. Pittenger AL, Westberg S, Rowan M, Schweiss S. An interprofessional diabetes experience to improve pharmacy and nursing students' competency in collaborative practice. Am J Pharm Educ. 2013;77(9):Article 197.

16. Kostoff M, Burkhardt C, Winter A, Shrader S. An interprofessional simulation using the sbar communication tool. $\mathrm{Am} \mathrm{J}$ Pharm Educ. 2016;80(9):Article 157.

17. Lucas C, Power T, Hayes C, Ferguson C. Development of the ripe model (reflective interprofessional education model) to enhance interprofessional collaboration. Res Soc Adm Pharm. 2019;15:459-464. 18. Lucas C, Power T, Hayes C, Ferguson C. "Two heads are better than one"- pharmacy and nursing students' perspectives on interprofessional collaboration utilizing the RIPE model of learning. Res Soc Adm Pharm. 2020;16:25-32. 